\title{
CRYSTAL STRUCTURE OF (1,4-DIHYDROXYNAPHTHALEN-2-YL) (4'-METHOXYPHENYL) METHANONE
}

\author{
JULIO BENITES ${ }^{1}$, JAIME A. VALDERRAMA ${ }^{1}$, DAVID RÍOS ${ }^{I}$, \\ ALEJANDRO CÁRDENAS IVÁN BRITO*3 \\ ${ }^{1}$ Facultad de Ciencia de la Salud, Universidad Arturo Prat, Casilla 121, Iquique, Chile. \\ ${ }^{2}$ Departamento de Física, Facultad de Ciencias Básicas, Universidad de Antofagasta, Casilla 170, Antofagasta, 1240000, Chile, \\ ${ }^{3}$ Departamento de Química, Facultad de Ciencias Básicas, Universidad de Antofagasta, Casilla 170, Antofagasta, 1240000, Chile.
}

\begin{abstract}
Solar photoacylation of 1,4-naphthoquinone with 4-methoxybenzaldehyde to give (1,4-dihydroxynaphthalen-2-yl)(4'-methoxyphenyl) methanone is one representative example of a general procedure to prepare highly functionalized 1,4-dihydroxynaphthalen-2-yl)(phenyl) methanone derivatives. The structure of the title compound was confirmed by x-ray diffraction analysis of a suitable single crystal.
\end{abstract}

Keywords: Solar light; quinones; diaryl methanones; X-ray diffraction.

\section{INTRODUCTION}

The Friedel-Crafts aromatic acylation is the most import route for the synthesis of aromatic ketones that are intermediates in manufacturing fine and speciality chemicals as well as pharmaceutical [1]. Photochemical reactions carried out with sunlight are particularly interesting in the context of green chemistry due to substrate activation often occurs without additional reagents, which diminishes formation of by products, and the renewable nature of the energy source $[2,3]$. Over the last few decades, the growing demand for environmentally friendly technologies has attracted rising attention in synthetic organic photochemistry [4]. Solar photoacylation of 1,4-naphthoquinone with 4-methoxybenzaldehyde to give (1,4-dihydroxynaphthalen-2-yl) (4'-methoxyphenyl) methanone is one representative example of solar lightmediated synthesis in the field of 1,4-dihydroxynaphthalen-2-yl)(phenyl) methanone derivatives. The structure of the new compound was elucidated by 1D and 2D NMR experiment and was confirmed by X-ray diffraction analysis of a single crystal obtained by slow evaporation of an ethyl acetate solution.

\section{EXPERIMENTAL}

1,4-Naphthoquinone $(1 \mathrm{mmol})$ and 4-methoxybenzaldehyde $(7.5 \mathrm{mmol})$ were placed into a pyrex glass tube, nitrogen was bubbled through the solution for $2 \mathrm{~min}$ and then sealed with a septum. The mixture was irradiated for six days (total illumination time of $30 \mathrm{~h}$ ), under solar radiation conditions in the range 800-1100 Watts $/ \mathrm{m}^{2}$ (December-March) [5]. The mixture reaction was chromatographed on silica gel ( $3: 1$ petroleum ether/ethyl acetate) to give pure (1,4-dihydroxynaphthalen-2-yl)(4'-methoxyphenyl)methanone as yellow crystals in $69 \%$ yield. Analysis: Solid crystalline m.p. $150-151{ }^{\circ} \mathrm{C}$. IR $(\mathrm{KBr})$ $v_{\mathrm{cm}^{-1}}: 3470(\mathrm{O}-\mathrm{H}), 1631(\mathrm{C}=\mathrm{O}) .{ }^{1} \mathrm{H}-\mathrm{NMR}\left(400 \mathrm{MHz}, \mathrm{CDCl}_{3}\right): \delta 3.86(\mathrm{~s}$, $3 \mathrm{H}, \mathrm{OMe}), 6.97\left(\mathrm{~d}, 2 \mathrm{H}, J=8.7 \mathrm{~Hz}, 2^{\prime}-\mathrm{H}+3^{\prime}-\mathrm{H}\right.$ or $\left.5^{\prime}-\mathrm{H}+6^{\prime}-\mathrm{H}\right), 7.02(\mathrm{~s}, 1 \mathrm{H}$, $3-\mathrm{H}), 7.56(\mathrm{t}, 1 \mathrm{H}, J=7.4 \mathrm{~Hz}, 6-\mathrm{H}$ or $7-\mathrm{H}), 7.65(\mathrm{t}, 1 \mathrm{H}, J=7.4 \mathrm{~Hz}, 7-\mathrm{H}$ or $6-\mathrm{H})$ $7.75\left(\mathrm{~d}, 2 \mathrm{H}, J=8.7 \mathrm{~Hz}, 6^{\prime}-\mathrm{H}+5^{\prime}-\mathrm{H}\right.$ or $\left.3^{\prime}-\mathrm{H}+2^{\prime}-\mathrm{H}\right), 8.20(\mathrm{~d}, 1 \mathrm{H}, J=8.3 \mathrm{~Hz}$, 5 -H or $8-\mathrm{H}), 8.47$ (m, $2 \mathrm{H}, 8-\mathrm{H}$ or $5-\mathrm{H}+4-\mathrm{OH}), 13.43(\mathrm{~s}, 1 \mathrm{H}, 1-\mathrm{OH}) ;{ }^{13} \mathbf{C}-\mathbf{N M R}$ $\left(100 \mathrm{MHz}, \mathrm{CDCl}_{3}\right): \delta 55.5,107.8,111.9,113.5,122.3,124.2,125.9,126.1$, $129.3(2 \times \mathrm{C}), 129.8,130.9,131.6(2 \times \mathrm{C}), 144.1,157.2,162.4,199.6$; HRMS (APCI): $[\mathrm{M}+\mathrm{H}]^{+}$calcd for $\mathrm{C}_{18} \mathrm{H}_{14} \mathrm{O}_{4}: 295.08921$; found: 295.08059 . Single crystal structural X-ray diffraction was carried out on a Enraf Nonius CAD4 diffractometer with graphite-monochromated MoK $\alpha$ radiation ( $0.71073 \AA$. The structure was solved by direct method, and was refined against $\mathrm{F}^{2}$ by full-matrix least-squares methods using SHELXL [6]. All of the nonhydrogen atoms were refined anisotropically. The hydrogen atoms attached to $\mathrm{C}$ and $\mathrm{O}$ atoms were located from a difference Fourier map and included at calculated positions and refined using a riding model .The final Fourier maps, the electron-density residuals were not significant. Crystallographic data, details of data collection and structure refinement parameters for the title compound is summarized in Table 1. Program used to solve structure: SHELXS-2013, program used to refine structure: SHELXL-2013[6] molecular graphics [7].

\section{RESULTS AND DISCUSSION}

The structure of the title compound was confirmed by x-ray diffraction analysis of a suitable single crystal (Fig.1). Yellow block crystals of (1,4-dihydroxynaphthalen-2-yl)(4'-methoxyphenyl) methanone approximate dimensions $0.048 \times 0.123 \times 0.164 \mathrm{~mm}$ were obtained by slow evaporation of a ethyl acetate solution. The fragment 1,4-dihydroxynaphthalen-2-yl is planar (rms deviations $0.017 \AA$ ) and make a dihedral angle of $41.37(15)^{\circ}$ with the methoxy phenyl fragment. All $\mathrm{OH}$ groups are involved in hydrogen bonding interactions with the average $\mathrm{H} \cdots \mathrm{O}$ distance of $1.94 \AA$ and $\mathrm{O}-\mathrm{H} \cdots \mathrm{O}$ angles of $146.5^{\circ}$, so in the crystal packing the molecules are associated by one strong intermolecular hydrogen bonds forming chain with graph-set motif $\mathrm{C}(11)$ along $\mathrm{b}$ axis. One strong intramolecular hydrogen bond is observed between hydroxyl and carbonyl groups, which stabilized the molecular conformation, Table 2 .The packing also features and $\pi-\pi$ stacking interactions between the fragment [Cg1-Cg2 $3.698(2) \AA ̊$; symmetry code (i) $-1+\mathrm{x}, \mathrm{y}, \mathrm{z} ; \mathrm{Cg} 1=\mathrm{C} 4 \mathrm{~A} / \mathrm{C} 5 /$ $\left.\mathrm{C} 6 / \mathrm{C} 7 / \mathrm{C} 8 / \mathrm{C} 8 \mathrm{~A} ; \mathrm{Cg} 2^{2}=\mathrm{C} 1 / \mathrm{C} 2 / \mathrm{C} 3 / \mathrm{C} 4 / \mathrm{C} 4 \mathrm{~A} / \mathrm{C} 8 \mathrm{~A}\right]$, Fig.3.All bond distances and angles are normal.

Table 1. Crystallographic data, details of data collection and structure refinement parameters for the title compound.



Crystal data

$\mathrm{C}_{18} \mathrm{H}_{14} \mathrm{O}_{4}$

$\mathrm{Mr}=294.29$

Monoclinic, P 21/n ( $\left.\mathrm{N}^{\circ} 14\right)$

$\mathrm{a}=4.5160(9) \AA \alpha=90^{\circ}$

$\mathrm{b}=10.949(2) \AA \beta=93.09(3)^{\circ}$

$\mathrm{c}=27.769(6) \AA \gamma=90^{\circ}$

Density (calculated)/Mg/m³ 1.426

Data Collection

Enraf Nonius CAD4 diffractometer

10472 measured reflections

2702 independent reflections

Theta range for data collection $(\theta)$

Index ranges

Refinement

$\mathrm{R}\left[\mathrm{F}^{2}>2 \sigma\left(\mathrm{F}^{2}\right)\right]=0.0483$

$\mathrm{wR}\left[\mathrm{F}^{2}\right]=0.0853$

$$
\begin{aligned}
& V=1371.1(5) \AA^{3} \\
& Z=4 \\
& \text { MoK } \alpha \text { radiation } \\
& \mu=0.101 \mathrm{~mm}^{-1} \\
& T=293(2) \mathrm{K} \\
& \text { yellow block } 0.048 \times \\
& 0.123 \times 0.164 \mathrm{~mm} \\
& \mathrm{~F}(000)=616
\end{aligned}
$$

905 reflections with

$\mathrm{I}>2 \sigma(\mathrm{I})$

$\mathrm{R}_{\text {int }}=0.2475$

1.469 to $25.991^{\circ}$

$-5<=\mathrm{h}<=5,-13<=\mathrm{k}<=13$, $-34<=1<=34$

200 parameters

$\mathrm{S}=0.944$

$\Delta \rho_{\max }=0.180 \mathrm{e} \cdot \AA^{-3}$

$\Delta \rho_{\text {min }}=-0.216 \mathrm{e} \cdot \AA^{-3}$ 


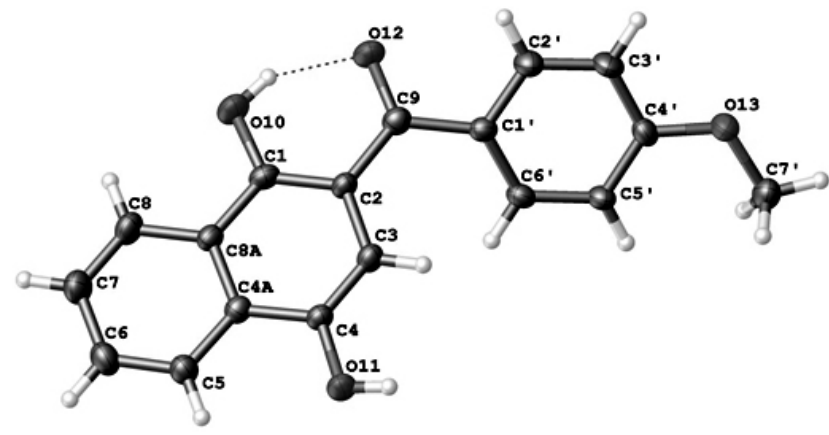

Fig. 1: ORTEP drawing of the molecular structure of the title compound.

Table 2: Hydrogen-bonding geometry $\left(\AA,^{\circ}\right)$.

\begin{tabular}{|c|c|c|c|c|}
\hline $\mathrm{D}-\mathrm{H} \cdots \mathrm{A}$ & $\mathrm{D}-\mathrm{H}$ & $\mathrm{H} \cdots \mathrm{A}$ & $\mathrm{D} \cdots \mathrm{A}$ & $\mathrm{D}-\mathrm{H} \cdots \mathrm{A}$ \\
\hline $\mathrm{O} 10-\mathrm{H} 10 \cdots \mathrm{O} 12$ & 0.82 & 1.79 & $2.507(4)$ & 146 \\
\hline $\mathrm{O} 11-\mathrm{H} 11 \cdots \mathrm{O} 13^{\mathrm{i}}$ & 0.82 & 2.08 & $2.800(4)$ & 147 \\
\hline
\end{tabular}

Symemetry codes: (i) $1 / 2-\mathrm{x},-1 / 2+\mathrm{y}, 1 / 2-\mathrm{z}$
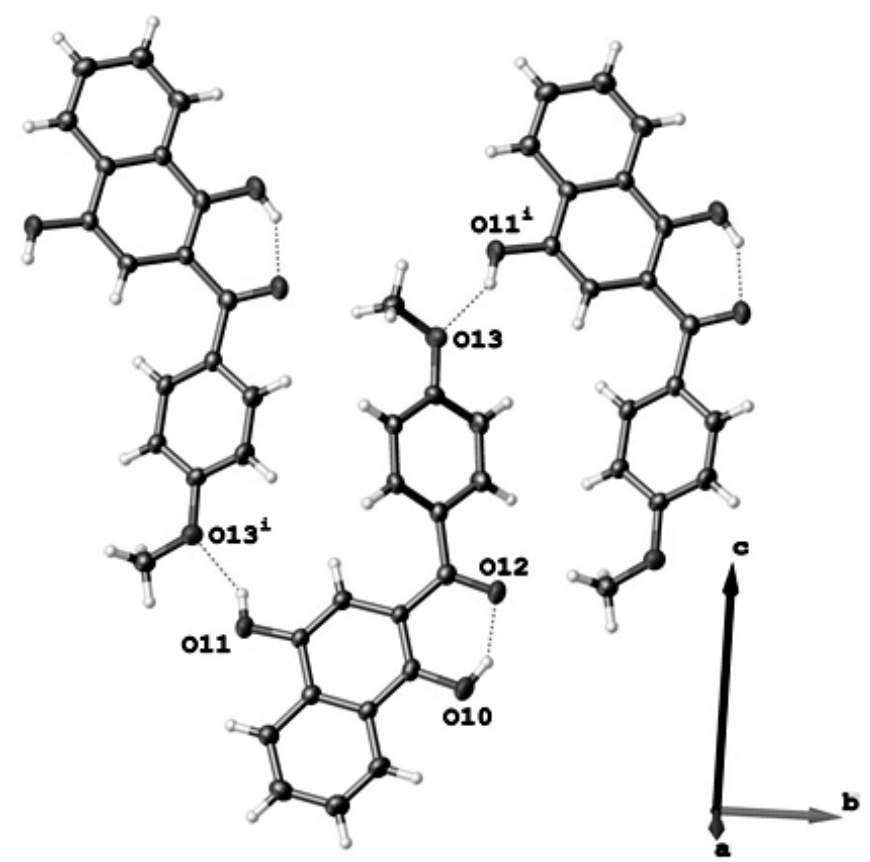

Fig. 2. A view of the one-dimensional supramolecular aggregate, showing the formation of chain with set-graph motif C (11) [Symmetry code: (i) $1 / 2-x$, $-1 / 2+y, 1 / 2-z$.]

\section{CONCLUSIONS}

All $\mathrm{OH}$ groups are involved in hydrogen bonding interactions with the average $\mathrm{H} \cdots \mathrm{O}$ distance of $1.94 \AA$ and $\mathrm{O}-\mathrm{H} \cdots \mathrm{O}$ angles of $146.5^{\circ}$, so in the crystal packing the molecules are associated by one strong intermolecular hydrogen bonds forming chain with graph-set motif $\mathrm{C}(11)$ along $\mathrm{b}$ axis. One strong intramolecular hydrogen bond is observed between hydroxyl and carbonyl groups, which stabilized the molecular conformation.

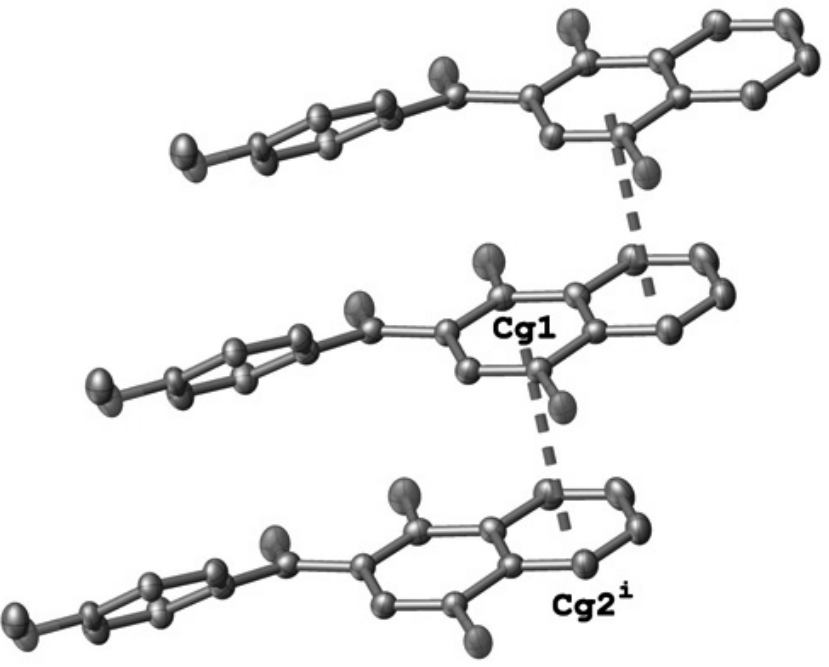

Fig.3 Part of the crystal structure of the title compound, showing the $\pi-\pi$ stacking interactions. $\mathrm{Cg} 1-\mathrm{Cg} 22^{\mathrm{i}} 3.698(2) \AA$; symmetry code (i) $-1+\mathrm{x}, \mathrm{y}, \mathrm{z} ; \mathrm{Cg} 1$ $\left.=\mathrm{C} 4 \mathrm{~A} / \mathrm{C} 5 / \mathrm{C} 6 / \mathrm{C} 7 / \mathrm{C} 8 / \mathrm{C} 8 \mathrm{~A} ; \mathrm{Cg} 2^{\mathrm{i}}=\mathrm{C} 1 / \mathrm{C} 2 / \mathrm{C} 3 / \mathrm{C} 4 / \mathrm{C} 4 \mathrm{~A} / \mathrm{C} 8 \mathrm{~A}\right]$.

\section{ACKNOWLEDGEMENTS}

The authors thank FONDECYT (Chile) (Grant $N^{\circ}$ 1100376) for financial support. We also acknowledge Fondequip (EQM130021) for the funding to purchase the $\mathrm{X}$ - ray diffractometer.

\section{Supplementary material}

CCDC- 1480801 contains the supplementary crystallographic data for this article. These data can be obtained free of charge from the Cambridge Crystallographic Data Centre via www.ccdc.cam.ac.uk/data_request/cif.

\section{REFERENCES}

1. Olah, G. A. in Friedel-Crafts and Related Reactions, vols. I-IV, Wiley/ Interscience, New YorK, 1963-1964;. Olah, G. A. in: Friedel-Crafts and Related Reactions, Wiley/Interscience, New York, 1973.

2. Albini, A.; Fagnoni. M.: Green chemistry and photochemistry were born at the same time. Green Chem., 6, (2004), 1-6.

3. Tundo, P.; Anastas, P.; StC. Black, D.; Breen, J.; Collins, T.; Memoli, S.; Miyamoto, J.; Poliakoff, M.; Tumas, W.: Synthetic pathways and processes in green chemistry. Introductory overview. Pure Appl. Chem., 72, (2000), 1207-1228.

4. Benites, J.; Cortes, M.; Miranda, L.; Estela, C.; Ríos, D.; Arenas, J.; Valderrama, J. A.: Green Synthetic approaches to furoylnaphthohydroquinone and juglone. J. Ch. Chem. Soc. 59 (2014) 2455-2457.

5. Arenas, P.; Peña, A.; Ríos D.; Benites, J. Muccioli, G. G.; Buc Calderón, P.; Valderrama, J. A.: Eco-Friendly Synthesis and Antiproliferative Evaluation of Some Oxygen Subtituted Diaryl Ketones. Molecules 18 (2013) 9818-9832.

6. Sheldrick, G. M.: A short history of SHELX. Acta Cryst. A64, (2008), $112-122$

7. Dolomanov, O.V.; Bourhis, L.J.; Gildea, R.J.; Howard, J.A.K.; Puschmann, H.: OLEX2: a complete structure solution, refinement and analysis program. J. Appl. Cryst. 42, (2009), 339-341 